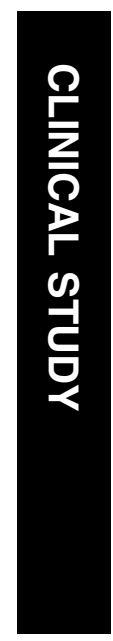

\title{
Long-term results of autogenous palmaris longus frontalis sling in children with congenital ptosis
}

\begin{abstract}
Purpose To investigate the long-term outcome of using autogenous palmaris longus tendon (PLT) sling for correcting congenital ptosis in children.

Methods This is an observational case series involving 15 eyelids of 14 consecutive children with congenital ptosis who underwent frontalis suspension surgery using PLT in a university teaching hospital.

Results One child had bilateral ptosis and the other children had unilateral ptosis. The age of patients at the time of surgery ranged from 2 to 7 years, with an average of 4.7 years. At a mean follow-up of 92 months (range, 80-104 months), all eyelids were successfully corrected with good lid height. No recurrence or other postoperative complications were encountered except one patient who developed a small skin fold over the PLT harvest site.

Conclusion Long-term lid position is remarkably stable after surgical correction using PLT. PLT sling appears to be a safe and effective treatment for children with congenital ptosis requiring frontalis sling operation. It could be a good alternative to autogenous fascia lata, and further studies, to compare these two sling materials seem warranted.
\end{abstract}

Eye (2005) 19, 546-548. doi:10.1038/sj.eye.6701539

Published online 20 August 2004

Keywords: palmaris longus tendon; ptosis; frontalis sling operation

Received: 4 November 2003 Accepted: 25 February 2004 Published online: 20 August 2004

Financial and proprietary interest: Nil.

Financial Support: Nil.

\section{Introduction}

Frontalis suspension has long been the surgical procedure of choice for correcting congenital
CY Wong ${ }^{1,2}$, DSP Fan ${ }^{1,2}$, JSK Ng ${ }^{1,2}$, TYH Goh ${ }^{1,2}$ and DSC Lam ${ }^{1,2}$ ptosis with poor levator function. Fresh autogenous fascia lata (FL) is considered the best material for frontalis suspension because of its potentially permanent effect as a 'livingsuture'. When sufficient amount of autogenous FL cannot be harvested in young children, an alternative material has to be looked for. Banked FL and synthetic materials such as monofilament nylon, silicone, and polytetrafluorethylene had been used as substitutes, but none appeared to be ideal. Palmaris longus tendon (PLT) is the most popular donor tendon for grafting procedures in orthopaedics. Like other tendons, PLT is composed of densely and regularly arranged connective tissues, thereby giving it more tensile strength than an equal portion of FL that contains irregularly arranged connective tissues. PLT could be a potentially better sling material than FL because of its cable-like feature and availability below the age of three, in addition to its better tensile strength. We reported its successful use for ptosis correction in adults in $1996,{ }^{1}$ then in children in $1998 .^{2}$ The mean follow-up for the study in children was 30 months. The longer-term follow-up study reported here would help evaluate the permanency of PLT as a living suture, as commented by Naugle. ${ }^{3}$

\section{Materials and methods}

The original study ${ }^{2}$ was an interventional, consecutive case series conducted at Prince of Wales Hospital, Hong Kong. Frontalis suspension surgery using PLT was performed in 15 eyelids of 14 consecutive children with congenital ptosis between 1994 and 1997. All surgeries were performed by one of us (DSCL). Details of the surgical techniques had been described previously. ${ }^{1,2}$ 
All the patients were called back for evaluation between August and September 2003. The postoperative surgical outcome (lid height), changes in best-corrected visual acuity between this and the last follow-ups in 1997, postoperative ocular complications, for example knot exposure and exposure keratitis, etc, subjective satisfaction about the postoperative eyelid position (from poor, moderate to good), appearance of the surgical scar (from poor, moderate to good) of the donor sites and functional status of the hand and forearm with the tendon harvested were assessed. Surgical outcome was judged as good, moderate, or poor, based on the criteria described by Manners. ${ }^{4}$

- Good: the postoperative lid position was maintained within $1 \mathrm{~mm}$ of the normal lid position ( $1 \mathrm{~mm}$ below the superior limbus) in the primary position of gaze.

- Moderate: the postoperative lid position dropped more than $1 \mathrm{~mm}$ below the normal lid position but remained clear of the visual axis in the primary position of gaze.

- Poor: the postoperative lid position dropped to obscure the visual axis in the primary position of gaze.

\section{Results}

All patients were available for evaluation. The mean age of the patients was 10.5 years (range, 8-13 years). At a mean follow-up of 92 months (range, 80-104 months), all patients had good correction of ptosis with no recurrence (Table 1). The best-corrected visual acuity in all eyes was stable and there were neither complications associated with the frontalis suspension procedure nor neurological deficits related to tendon harvest. Surgical scars over the incision sites for PLT harvest were small and inconspicuous (Figure 1). Although there was a small skin fold over the distal incision site of the forearm in Patient 13, she was not bothered by it (Figure 2). All patients and their parents were satisfied with the postoperative eyelid position and the appearance of surgical scars over the donor sites.

\section{Discussion}

An ideal material for frontalis suspension surgery should possess the following characteristics: good availability, ease of harvest and handling, inertness, and permanency as a living-suture. Fresh autogenous FL is regarded as the best material for the procedure because of its presumed long-lasting effect. However, recurrence remains a problem and Wasserman ${ }^{5}$ reported a recurrence rate of $4.2 \%$ at a median follow-up of 60 months. Moreover, in patients younger than 3 years of age, the iliotibial tract in the leg is not fully developed that may preclude the use
Table 1 Results of brow suspension with the palmaris longus tendon

\begin{tabular}{llcrl}
\hline $\begin{array}{l}\text { Patient, sex, age } \\
\text { (years) }\end{array}$ & $\begin{array}{l}\text { Upper } \\
\text { eyelid }\end{array}$ & $\begin{array}{r}\text { Ptosis } \\
(\mathrm{mm})\end{array}$ & $\begin{array}{r}\text { Follow-up } \\
\text { (months) }\end{array}$ & Results \\
\hline${ }^{\mathrm{a}}$ 1, M, 6 & Right & 3 & 89 & Good \\
1, M, 6 & Left & 3 & 89 & Good \\
2, M, 5 & Right & 3 & 97 & Good \\
3, M, 7 & Left & 4 & 100 & Good \\
4, M, 5 & Right & 2 & 94 & Good \\
5, F, 7 & Right & 4 & 101 & Good \\
6, F, 4 & Right & 3 & 90 & Good \\
7, M, 4 & Right & 3 & 93 & Good \\
8, M, 5 & Right & 3 & 93 & Good \\
9, M, 5 & Left & 3 & 86 & Good \\
10, M, 3 & Left & 3 & 83 & Good \\
11, M, 2 & Right & 3 & 79 & Good \\
12, F, 3 & Right & 3 & 81 & Good \\
13, M, 6 & Right & 3 & 80 & Good \\
14, M, 6 & Left & 3 & 77 & Good \\
\hline
\end{tabular}

Good: defined as the postoperative lid position was maintained within $1 \mathrm{~mm}$ of the normal lid position ( $1 \mathrm{~mm}$ below the superior limbus) in the primary position of gaze.

aSame patient receiving brow suspension surgery in both eyes using the same palmaris longus tendon.
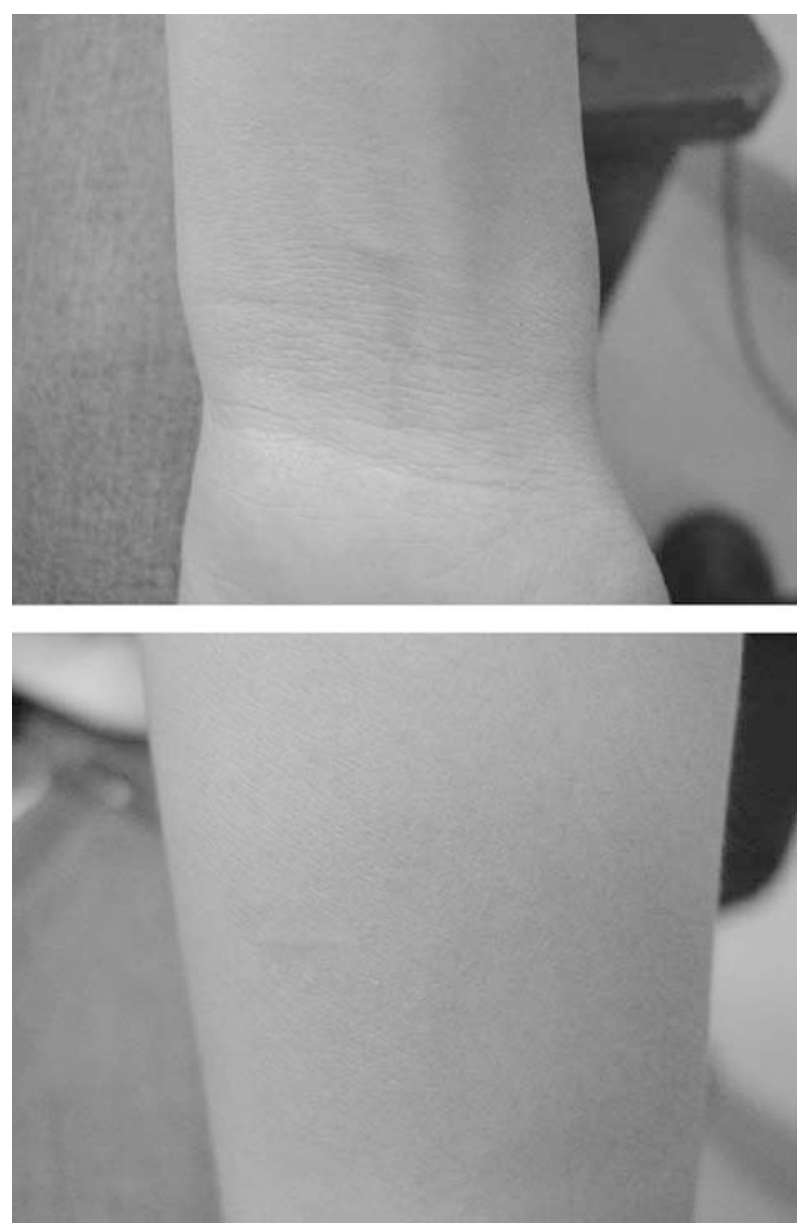

Figure 1 Postoperative photographs showing small and inconspicuous scar at incision sites of Patient 6. 


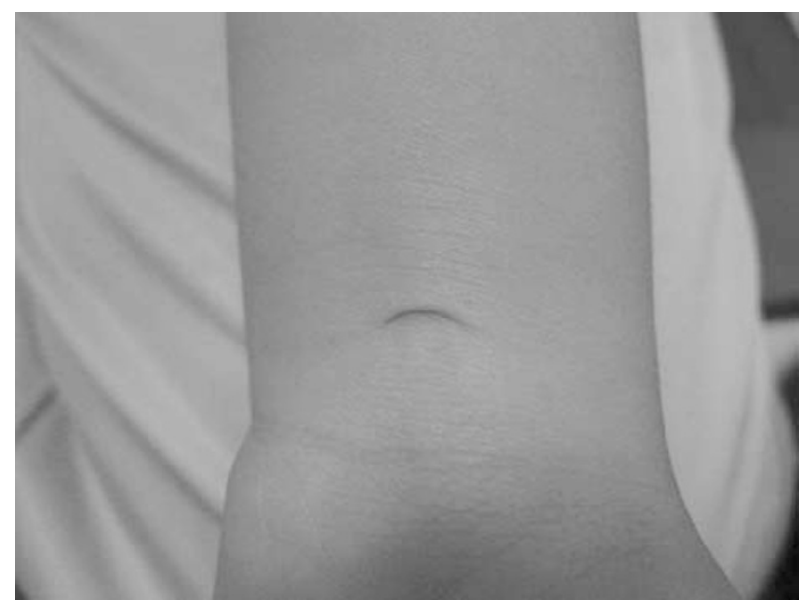

Figure 2 Postoperative photograph showing the skin fold at incision site of Patient 13

of autogenous FL. Banked FL has not been a good substitute because of its high recurrence rate, for example $51.4 \%$ at a mean follow-up of 41 months reported in one study. ${ }^{5}$ Synthetic materials, such as prolene, ${ }^{4}$ monofilament, ${ }^{5}$ silicone and mersilene ${ }^{6,7}$ are available as alternatives. Most reports involving synthetic materials tend to be small series with limited follow-up.

Recurrence is expected to be more common with a longer period of follow-up.

PLT, a vestigial tendon, and the most popular donor tendon for grafting procedures in orthopaedics possesses many features of an 'ideal' sling material. It is completely developed at birth and can be harvested in sufficient length for brow suspension in most age groups, including the very young in whom the FL has not been adequately developed. For instance, Patient 11 received the operation at the age of 2 years. Being autogenous in nature, it is well tolerated by the body. The tendon is composed of dense and regularly arranged connective tissues, thereby giving it more tensile strength than a same portion of FL. The superficial location of PLT makes harvesting relatively easy. However, PLT is found in about $80 \%$ of the population and its presence must be confirmed preoperatively. All major complications of the PLT harvest came from patients with absence of PLT. ${ }^{8}$ In its absence, the median nerve may be mistaken as the PLT. ${ }^{8}$ In our studies, ${ }^{1,2}$ we did not encounter any morbidity associated with the harvest. The theoretical risk of damage to adjacent structures, especially the median nerve, is not likely to materialize in practice if the surgeon has received proper training and the presence of PLT is ascertained preoperatively. ${ }^{1,2}$ Lastly, the cosmetic appearance over the harvest sites were good, and none of our patients or their parents were concerned or dissatisfied with it.

Biomechanical properties of the sling materials are important when their potential to be a permanent livingsuture is considered. A tendon may be more optimal because of the stiffer biomechanical properties. It is premature to conclude that PLT will not fail in the long run but theoretically PLT has a potential to survive for a longer period when compared with FL. Results of this study are in support of this idea. However, this study needs to be viewed in the light of several limitations. It was a small series with no control group. All the surgeries were performed only by one of us (DSCL). The favourable surgical results, in terms of the stable and satisfactory lid position in primary gaze, among our patients with long-term follow-up speak for the potential value of the PLT sling operation. Further studies to compare the safety and efficacy of autogenous PLT and FL as sling materials seem warranted.

\section{References}

1 Lam DSC, Lam TP, Chen IN, Tsang GH, Gandhi SR. Palmaris longus tendon as a new autogenous material for frontalis suspension surgery in adults. Eye 1996; 10: 38-42.

2 Lam DSC, Ng JSK, Cheng GPM, Li RTH. Autogenous palmaris longus tendon as frontalis suspension material for ptosis correction in children. Am J Ophthalmol 1998; 126: 109-115.

3 Naugle TC, Faust DC. Letter to the Editors: autogenous palmaris longus tendon as frontalis suspension material for ptosis correction in children. Am J Ophthalmol 1999; 127: 488-489.

4 Manners RM, Tyers AG, Morris RJ. The use of prolene as a temporary suspensory material for brow suspension in young children. Eye 1994; 8: 346-348.

5 Wasserman BN, Sprunger DT, Helveston EM. Comparison of materials used in frontalis suspension. Arch Ophthalmol 2001; 119: $687-691$.

6 Lam DSC, Gandhi SR, Ng JSK, Chen IN, Kwok PSK, Chan GH. Early correction of severe unilateral infant ptosis with the Mersilene mesh sling. Eye 1997; 11: 806-809.

7 Sharma TK, Willshaw H. Long-term follow-up of ptosis correction using Mersilene mesh. Eye 2003; 17: 759-761.

8 Vastamaki M. Median nerve as free tendon graft. J Hand Surg 1987; 12: 187-188. 